\title{
A novel PDGF receptor inhibitor-eluting stent attenuates in-stent neointima formation in a rabbit carotid model
}

\author{
CHEN HUANG $^{1}$, HAIJUN MEI $^{1}$, MIN ZHOU $^{2}$ and XIAOBING ZHENG ${ }^{1}$ \\ ${ }^{1}$ Division of Vascular Surgery, Department of General Surgery, Affiliated Hospital of Nantong University, \\ Nantong, Jiangsu 226001; ${ }^{2}$ Department of Vascular Surgery, Nanjing Drum Tower Hospital, \\ The Affiliated Hospital of Nanjing University Medical School, Nanjing, Jiangsu 210008, P.R. China
}

Received October 4, 2015; Accepted July 20, 2016

DOI: $10.3892 / \mathrm{mmr} .2016 .5986$

\begin{abstract}
A novel drug-eluting stent (DES) is required to target vascular smooth muscle cells (SMCs) without harming endothelial cells (ECs). Platelet-derived growth factor (PDGF) is critical for the proliferation and migration of SMCs. Sunitinib [a PDGF receptor (PDGFR) tyrosine kinase inhibitor]-eluting stents may therefore inhibit neointimal formation. The aim of the present study was to examine the stent-based delivery of sunitinib in a rabbit carotid model; in addition, the effects of sunitinib were evaluated in vitro. Local administration of sunitinib markedly reduced neointimal formation without delaying re-endothelialization in the carotid artery model. In vitro, sunitinib inhibited SMC proliferation; however, no effects were observed on ECs. Sunitinib caused necrosis of SMCs. In addition, sunitinib attenuated PDGF-stimulated SMC migration in a scratch wound assay and inhibited $\alpha$-SMA cytoskeleton polymerization. Furthermore, sunitinib inhibited PDGF-induced phosphorylation of extracellular signal-regulated kinase in vitro and in vivo. Therefore, this novel DES may be a potential strategy for the treatment of vascular disorders.
\end{abstract}

\section{Introduction}

Percutaneous angioplasty, including stent implantation, is currently the most frequently performed medical procedure for vascular diseases. However, long-term success is limited

Correspondence to: Dr Xiaobing Zheng, Division of Vascular Surgery, Department of General Surgery, Affiliated Hospital of Nantong University, 20 Xishi Road, Nantong, Jiangsu 226001, P.R. China

E-mail: doctorzxb@sina.com

Dr Min Zhou, Department of Vascular Surgery, Nanjing Drum Tower Hospital, The Affiliated Hospital of Nanjing University Medical School, 321 Zhongshan Road, Nanjing, Jiangsu 210008, P.R. China

E-mail: zhouminnju@126.com

Key words: sunitinib, platelet-derived growth factor receptor inhibitor, drug-eluting stent, in-stent restenosis, re-endothelialization by in-stent restenosis, which occurs in $20-30 \%$ of all patients following intervention (1).

The primary underlying mechanism and pathology of in-stent restenosis has only recently been elucidated. Various events contribute to neointimal formation; of these, the migration and proliferation of vascular smooth muscle cells (VSMCs) is critical (2). Drug-eluting stents (DES) markedly reduce the restenosis rate via the controlled release of nonspecific antiproliferative agents, and are therefore a promising therapeutic strategy. However, these nonspecific drugs may cause endothelial toxicity, attenuating re-endothelialization and resulting in late in-stent thrombosis (3-6). Therefore, the identification of a novel therapeutic agent specifically targeting VSMCs is essential for the development of safer and more effective DES.

Platelet-derived growth factor (PDGF) is crucial for the proliferation and migration of VSMCs that results in restenosis $(7,8)$. Activation of the PDGF receptor (PDGFR) was observed a few days following the application of mechanical force. In addition, the expression of PDGF ligands and PDGFR has been detected in restenosis lesions $(9,10)$. Sunitinib malate (sunitinib) is a tyrosine kinase inhibitor of PDGFR, which only weakly inhibits vascular endothelial growth factor receptor. This agent exerts anticancer effects and has been widely used for the treatment of metastatic renal cell carcinoma and gastrointestinal stromal tumors $(11,12)$. Previous studies have administered sunitinib orally to prevent restenosis in a balloon-injury carotid artery model (13). However, systemic administration of a PDGFR inhibitor requires a relatively high dose, which may cause adverse effects. Clinical trials of imatinib (a PDGFR-targeting drug) detected no beneficial effects on in-stent restenosis when the agent was administered orally (100 mg/day for 10 days) (14). Therefore, the prevention of restenosis via sunitinib targeting of PDGF may require a local delivery system.

In the present study, it was hypothesized that a sunitinib-eluting stent (STES) may be an effective therapeutic strategy for the prevention of neointima formation in the rabbit carotid model. In addition, the effects of sunitinib on VSMCs were evaluated in vitro.

\section{Materials and methods}

Stent coating. Bare-metal stents (diameter, $2 \mathrm{~mm}$; length, $20 \mathrm{~mm}$ ) were purchased from Dalian Yinyi Biomaterials 
Development Co., Ltd. (Dalian, China). Sunitinib was obtained from CST Biological Reagents Co., Ltd. (Shanghai, China) and sunitinib-eluting stents were produced in our laboratory as previously described by Chen et al (15). Sunitinib was dissolved in $100 \mu \mathrm{l}$ ethanol and mixed with lubricating jelly (Jiangsu Province Jianerkang Medical Dressing Co., Ltd., Jintan, China) to a final concentration of $2 \mathrm{mg} / \mathrm{g}$ of jelly. Lubricating jelly is a commercially available product that consists of propylene glycol, a viscous liquid commonly used as an additive in food and medicine. Each balloon-mounted stent was individually dipped in sunitinib jelly to produce a thin coating weighing approximately $0.015 \mathrm{~g}$; the amount of sunitinib eluted was determined from the additional weight of the coating. The stents were air-dried to completely evaporate the solvent. A coated stent was crimped onto a shrunken catheter balloon, and a pressure of $10 \mathrm{~atm}$ was applied to make the stent expand fully. The amount of sunitinib prior to and following expansion was analyzed.

Sunitinib release was measured using high performance liquid chromatography (HPLC; Agilent 1100; Agilent Technologies, Inc., Santa Clara, CA, USA), as previously described (16). The STES was immersed in a tube containing phosphate-buffered saline (PBS; $\mathrm{pH}=7.35-7.45)$. All tubes were incubated at $37^{\circ} \mathrm{C}$ throughout the release study. Samples were characterized at each predetermined time point.

Animal preparation and stent implantation. All care and handling of the animals was in accordance with guidelines for the care and use of laboratory of animals, and the present study was approved by Nanjing University's ethical research committee (Nanjing, China). A total of 24 male New Zealand rabbits (2.5-3.5 kg) obtained from Jiangning Qinglongshan Animal Center (Nanjing, China), were used in the present study. Animals were maintained at $22^{\circ} \mathrm{C}$ and $65 \%$ humidity, and allowed ad libitum access to water and a basal diet. The rabbits were randomly assigned to two treatment groups: Bare-metal stent (BMS; $n=12$ ) and sunitinib-coated stents (STES; n=12). Under anesthesia with $5 \mathrm{mg}$ droperidol and 100 mg ketamine (Fujian Fukang Pharmaceutical Co., Ltd., Fuzhou, China) administered intramuscularly, the carotid artery was accessed by dissection and isolated from the surrounding tissue. The balloon-expandable stent was inserted into the carotid artery through a small incision, and the stent was deployed by inflation with $10 \mathrm{~atm}$. for $30 \mathrm{sec}$. Finally, the access site in the carotid artery was closed with 8-0 Prolene suture (Ethicon, Inc, Somerville, NJ, USA). Postoperatively, all rabbits received $25 \mathrm{mg}$ aspirin prior to sacrifice, and a prophylactic antibiotic (300 $\mathrm{mg}$ cefuroxime) was administered for 7 days. The implanted stents were monitored by a Doppler handle probe (HP Sonos 4500; Philips Medical Systems, Inc., Bothell, WA, USA), and images of the blood flow were recorded every month. Diagnostic angiography was performed to confirm the position and patency rate of the stents.

Tissue harvest and pathological sample preparation. At 1-3 months following stent implantation, rabbits were euthanized by direct intracardiac injection of potassium chloride and the stents and surrounding arteries were harvested. The arteries containing stents were divided into three segments. The proximal segment was opened longitudinally, flattened and fixed in $1.6 \%$ glutaraldehyde. It was then dehydrated, dried with $\mathrm{CO}_{2}$, coated with gold and visualized under a scanning electron microscope (SEM; 3600N; Hitachi, Ltd., Tokyo, Japan). The percentage of the re-endothelialized area compared with the total luminal surface area was determined by examining SEM photomicrographs of each specimen. Protein was extracted from the ventral segment for western blot analysis. The distal segment was fixed in $10 \%$ neutral-buffered formalin for $24 \mathrm{~h}$, embedded in methylmethacrylate, circumferentially cross-sectioned into $5-\mu \mathrm{m}$ thick sections on a microtome fitted with a D-profile tungsten carbide knife (Delaware Diamond Knives, Inc., Wilmington, DE, USA) and stained with hematoxylin and eosin (17) for the quantification of histomorphological parameters. Tissue sections were visualized using a light microscope (BX51; Olympus Corporation, Tokyo, Japan), and the injury score (IS), average intimal thickness (AIT), areas of neointima (AN), media area, fibrin score (FI) and inflammation score (IMS) of each section was measured by digital morphometry using Image-Pro Plus software version 6.2 (Media Cybernetics, Inc., Rockville, MD, USA). IS was graded using the standardized protocol developed by Schwartz et al (18), which determined the degree of injury of the vessel wall in a semi-quantitative manner. The maximum score of 3 was applied when medial laceration extended through the external elastic lamina, and a score of 0 corresponded to an intact internal elastic lamina. Similarly, the extent of cellular infiltration was scored from 0-3 using a system described by Hong et al (19).

Cell proliferation analysis in vitro. Rat smooth muscle cells (RSMCs) and rat endothelial cells (RECs) were purchased from the Cell Bank of the National Academy of Science (Shanghai, China). RSMCs were grown in Dulbecco's modified Eagle's medium (DMEM) (Sigma-Aldrich; Merck Millipore, Darmstadt, Germany) containing 10\% fetal bovine serum (FBS; Sigma-Aldrich; Merck Millipore). RECs were cultured in Endothelial Basal Medium 2 (Sigma-Aldrich; Merck Millipore). Rat SMCs/ECs were chosen for the present preliminary study as rat antibodies are more commonly available. RSMCs and RECs were seeded in 96-well culture plates (7,500 cells/well). Sunitinib $(0.1,1$ or $10 \mu \mathrm{M})$ or vehicle was added to the wells. Two days later, a 3-(4,5-dimethylthiazol)-2,5-diphenyltetrazolium (MTT) assay was performed as described previously (20) to determine the cytotoxicity of sunitinib.

To assess the direct effect of sunitinib on the proliferation of RSMCs, a 3H-thymidine incorporation assay was performed. (Methyl-3H)-thymidine $(1 \mu \mathrm{Ci} / \mathrm{ml}$; PerkinElmer, Inc., Waltham, MA, USA) was added to wells $6 \mathrm{~h}$ prior to the termination of each experiment. Radioactivity was measured using a liquid scintillation counter.

Evaluation of apoptosis and necrosis in vitro. To detect cell death, cells were stained with annexin V-fluorescein isothiocyanate (FITC) and propidium iodide (PI) according to the manufacturer's instructions (BD Biosciences, San Jose, CA, USA). RSMCs were cultured in a serum-free medium in the presence or absence of sunitinib for $24 \mathrm{~h}$ and then stimulated with $20 \mathrm{ng} / \mathrm{ml}$ PDGF-BB (CST Biological Reagents Co., Ltd.) homodimers for a further $24 \mathrm{~h}$. The cells were subse- 
quently trypsinized, collected and incubated with $5 \mu$ annexin V-FITC and $5 \mu \mathrm{l} \mathrm{PI}$ (stock solution, $50 \mu \mathrm{g} / \mathrm{ml}$ ) for $30 \mathrm{~min}$ at room temperature in the dark. Apoptotic (annexin $\mathrm{V}^{+} / \mathrm{PI}^{-}$) and necrotic (annexin $\mathrm{V}^{+} / \mathrm{PI}^{+}$) cells were detected on a FACSCalibur (BD Biosciences).

RSMC attachment assay in vitro. RSMCs were cultured in 6 -well plates with BMS and STES for $12 \mathrm{~h}$ prior to examination. RSMCs attached to the stent struts were stained with 4,6-diamidino-2-phenylindole (DAPI; a blue fluorescent dye for cell nuclei) and observed under a fluorescent microscope. The numbers of attached SMCs were counted in three random high-power fields (magnification, x200) per strut.

Scratch wound assay. RSMCs were seeded in 35-mm dishes in DMEM and starved of FBS for $12 \mathrm{~h}$, and cells were scratched with a $100-\mu 1$ pipette tip. Cells were pretreated with $0,0.1,1$ or $10 \mu \mathrm{M}$ sunitinib and subsequently stimulated with $20 \mathrm{ng} / \mathrm{ml}$ PDGF-BB for $24 \mathrm{~h}$. Cells were visualized under a light microscope and images were captured. Image-Pro Plus software version 6.2 (Media Cybernetics, Inc., Rockville, MD, USA) was used for quantification.

$\alpha$-smooth muscle actin ( $\alpha$-SMA) cytoskeleton staining. RSMCs were seeded in 6-well culture plates in DMEM and starved of FBS for $24 \mathrm{~h}$, and treated with sunitinib or vehicle supplemented with $20 \mathrm{ng} / \mathrm{ml}$ PDGF-BB for a further $24 \mathrm{~h}$. RSMCs were fixed with $4 \%$ paraformaldehyde for $10 \mathrm{~min}$ and permeabilized in $0.2 \%$ Triton X-100 for $10 \mathrm{~min}$. The primary rabbit polyclonal anti- $\alpha$-SMA antibody (1:100; catalog no. 14968; CST Biological Reagents Co., Ltd.) was applied to cells. Following washing with PBS three times, cells were incubated with the secondary antibody FITC-anti-rabbit IgG (1:400; catalog no. ab6717; Abcam, Cambridge, MA, USA) for $2 \mathrm{~h}$ at $37^{\circ} \mathrm{C}$ and observed under a fluorescent microscope.

Western blot analysis. For the in vitro experiment, protein was extracted using radioimmunoprecipitation assay buffer (Sigma-Aldrich; Merck Millipore) from RSMC cultured with various concentrations of sunitinib and $20 \mathrm{ng} / \mathrm{ml}$ PDGF-BB. Protein $(20 \mu \mathrm{g})$ was loaded onto a $12 \%$ SDS-PAGE gel, separated by electrophoresis and transferred onto a polyvinylidene difluoride membrane. Membranes were blocked with $5 \%$ non-fat milk for $2 \mathrm{~h}$, and incubated overnight at $4^{\circ} \mathrm{C}$ with the following primary antibodies: Rabbit phosphorylated (p)-PDGFR- $\beta$ (1:1,000; catalog no. 3124), rabbit p-extracellular signal-regulated kinase (ERK; 1:1,000; catalog no. 9101) and rabbit glyceraldehyde-3-phosphate dehydrogenase (GAPDH; 1:2,000; catalog no. 5174), all purchased from CST Biological Reagents Co., Ltd. A horseradish peroxidase-conjugated goat anti-rabbit secondary antibody (1:3,000; catalog no. ab6721; Abcam) was then added to the membranes at room temperature for $2 \mathrm{~h}$. The signal was developed using Enhanced Chemiluminescence reagent (EMD Millipore, Bedford, MA) and visualized with the FlourChem FC2 Imaging System (ProteinSimple, San Jose, CA, USA). The protein bands were quantified using Image J software version $1.51 \mathrm{~b}$ (National Institutes of Health, Bethesda, MD, USA). For the in vivo experiment, protein from neointimal tissue and media plus adventitia from BMS and STES was extracted and the protein expression levels of p-ERK and GAPDH were analyzed.

Statistical analysis. Data are expressed as the mean \pm standard deviation. Unpaired Student's $t$-test was used to compare control and sunitinib-treated groups. Statistical analyses were performed in SPSS version 13.0 (SPSS, Inc., Chicago, IL, USA). $\mathrm{P}<0.05$ was considered to indicate a statistically significant difference.

\section{Results}

Stent coating. Incubation of bare-metal stents in the solution of sunitinib jelly resulted in coating with this compound in the present preliminary study; $32 \pm 5.4 \mu \mathrm{g}$ sunitinib was bound to the stent. The amount of sunitinib on the stent did not alter following expansion. The results of the in vitro release of sunitinib are presented in Fig. 1A.

STES reduces neointimal formation in rabbit carotid arteries. Stents were successfully implanted into the carotid arteries of 24 New Zealand rabbits (Fig. 1B), and the patency of the stent grafts was demonstrated by diagnostic angiography and Doppler ultrasound (Fig. 1C and D).

In-stent restenosis was examined by morphological analysis, as presented in Fig. 2. One month following implantation, the AIT was $0.12 \pm 0.03 \mathrm{~mm}$ in the BMS group and $0.07 \pm 0.04 \mathrm{~mm}$ in the STES group $(\mathrm{P}=0.06)$. Three months following implantation, clear neointimal formation was observed in BMS arteries; however, AIT was markedly reduced in STES $(0.16 \pm 0.06$ vs. $0.22 \pm 0.05 \mathrm{~mm} ; \mathrm{P}=0.03)$. In addition, the $\mathrm{AN}$ was $0.35 \pm 0.14 \mathrm{~mm}^{2}$ in the BMS group and $0.21 \pm 0.12 \mathrm{~mm}^{2}$ in the STES group $(\mathrm{P}=0.07)$ one month following implantation, and $0.64 \pm 0.20 \mathrm{~mm}^{2}$ in the BMS group and $0.50 \pm 0.21 \mathrm{~mm}^{2}$ in the STES group $(\mathrm{P}=0.09)$ three months following implantation (Fig. 2A and B).

No differences were observed in the IS or IMS between the two groups at one and three months following implantation, indicating that the observed effects on neointima formation did not result from structural differences or inflammation.

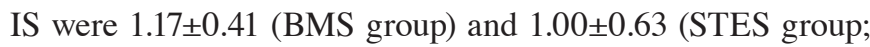
$\mathrm{P}=0.31$ ), and $1.16 \pm 0.41$ (BMS group) and 1.17 \pm 0.98 (STES group; $\mathrm{P}=0.50)$, at one and three months post-implantation, respectively. IMS were $0.33 \pm 0.52$ (BMS group) and $0.17 \pm 0.41$ (STES group; $\mathrm{P}=0.18$ ), and $0.33 \pm 0.52$ (BMS group) and $0.50 \pm 0.55$ (STES group; $\mathrm{P}=0.31$ ), at one and three months post-implantation, respectively.

Regarding the cytotoxicity of sunitinib, media area and FI were calculated. Media area was $0.42 \pm 0.03$ in the BMS group and $0.40 \pm 0.04$ in the STES group $(\mathrm{P}=0.21)$, and $0.42 \pm 0.06$ in the BMS group and $0.39 \pm 0.04$ in the STES group $(\mathrm{P}=0.25)$, at one and three months post-implantation, respectively. The FI values were $1.83 \pm 0.41$ (BMS) and 2.00 \pm 0 (STES; $\mathrm{P}=0.18)$, and $2.00 \pm 0$ (BMS) and 1.67 \pm 0.52 (STES; $\mathrm{P}=0.09)$, at one and three months post-implantation, respectively. These results suggest that local administration of sunitinib inhibited neointimal formation without damaging normal vascular media.

STES does not affect re-endothelialization. Re-endothelialization was analyzed by SEM. The 
A
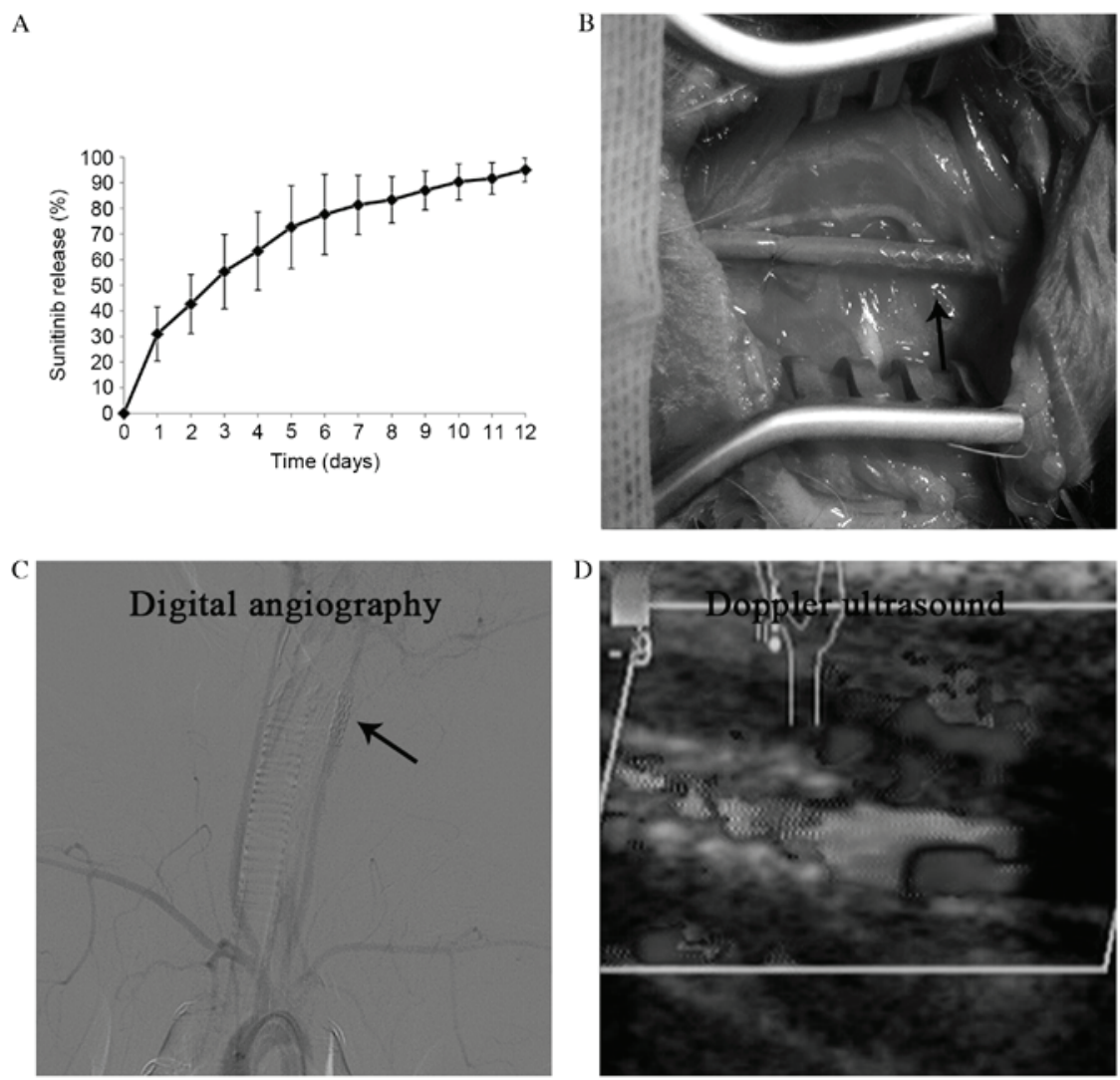

Figure 1. (A) Cumulative release profile of sunitinib from sunitinib-eluting stents. (B) Stent implantation. (C) Postoperative diagnostic angiography and (D) Doppler ultrasound demonstrated the patency of the stent grafts. The arrow indicates the position of the stent.

re-endothelialized areas at one month following implantation were $91.7 \pm 3.7$ and $89.5 \pm 6.8 \%$ in the BMS and STES groups, respectively $(\mathrm{P}=0.24$; Fig. $2 \mathrm{C})$, indicating that $\mathrm{BMS}$ and STES were efficient at inducing re-endothelialization. Notably, BMS and STES were observed to almost fully re-endothelialize areas, demonstrating that sunitinib did not delay endothelialization in the rabbit carotid model.

Sunitinib inhibits proliferation and induces necrosis in RSMCs. An MTT assay was performed in vitro with RSMCs and RECs to evaluate the effect of sunitinib on proliferation. Sunitinib treatment significantly suppressed the proliferation of RSMCs in a dose-dependent manner $(0.1 \mu \mathrm{M}, \mathrm{P}=0.040$; $1 \mu \mathrm{M}, \mathrm{P}=0.001 ; 10 \mu \mathrm{M}, \mathrm{P}<0.001)$; these suppressive effects were attenuated in RECs. No suppression was observed when RECs were treated with 0.1 or $1 \mu \mathrm{M}$ sunitinib. The proliferation of RECs was slightly inhibited at $10 \mu \mathrm{M}$ sunitinib (Fig. 3A). In addition, sunitinib treatment significantly suppressed DNA synthesis in RSMCs in a dose-dependent manner $(0.1 \mu \mathrm{M}$, $\mathrm{P}=0.014 ; 1 \mu \mathrm{M}, \mathrm{P}=0.021 ; 10 \mu \mathrm{M}, \mathrm{P}=0.021)$. However, sunitinib had no significant effects on DNA synthesis in RECs.

As an antiproliferative effect is often accompanied by apoptosis or necrosis, the apoptotic effects of sunitinib on RSMCs were examined. Sunitinib significantly increased necrosis in a dose-dependent manner $(0.1 \mu \mathrm{M}, \mathrm{P}=0.010$; $1 \mu \mathrm{M}, \mathrm{P}=0.015 ; 10 \mu \mathrm{M}, \mathrm{P}=0.009$ ), as assessed by $\mathrm{PI}$ staining, indicating that sunitinib may block RSMC proliferation by inducing necrosis (Fig. 3B). The in vitro effects of STES and BMS on RSMC adherence were then assessed. RSMC attachment to STES was reduced compared with BMS (21.8 \pm 9.3 vs. $11.2 \pm 5.4$ /strut; $\mathrm{P}=0.03$; Fig. 3 C).

Sunitinib-antagonizes PDGF-induced migration of RSMCs. Migration of SMCs from media to intima occurs following vascular injury, and PDGF is crucial for this migration. A scratch wound assay and cytoskeleton staining was therefore performed to investigate the effect of sunitinib on migration. The scratch wound assay is a classic two-dimensional migration model. As presented in Fig. 3D, stimulation with PDGF-BB induced migration was attenuated by sunitinib in a dose-dependent manner. Actin cytoskeleton polymerization is critical for cell migration; therefore, $\alpha$-SMA in RSMCs was visualized with FITC. Actin polymerization was decreased following sunitinib treatment (Fig. 3E), suggesting that downregulated expression levels of $\alpha$-SMA may represent one of the mechanisms underlying the inhibition of RSMC migration by sunitinib.

Sunitinib blocks PDGF-induced ERK phosphorylation. Various signaling pathways (particularly the ERK signaling pathway) are involved in SMC migration and growth. Therefore, ERK activation was analyzed by assessing phosphorylation, to further study the mechanisms underlying the inhibitory effects of sunitinib on proliferation and migration.

In the in vitro experiment, protein expression levels of p-PDGFR were decreased by sunitinib treatment in a dose-dependent manner, and PDGF-induced downstream p-ERK protein expression levels were suppressed $(0.1 \mu \mathrm{M}$, 
A

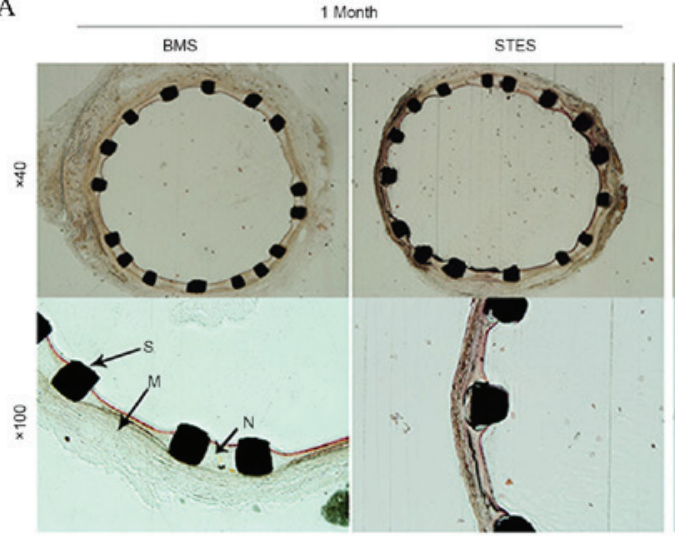

B

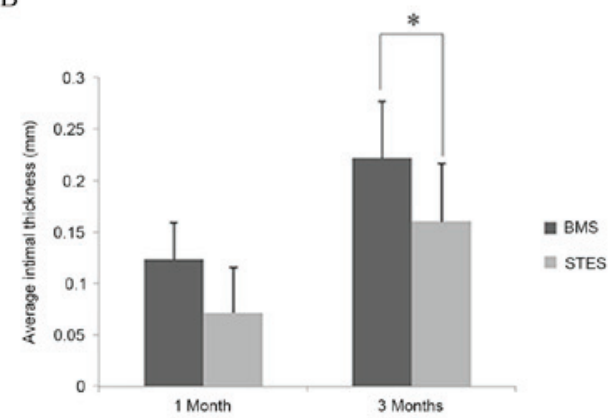

C
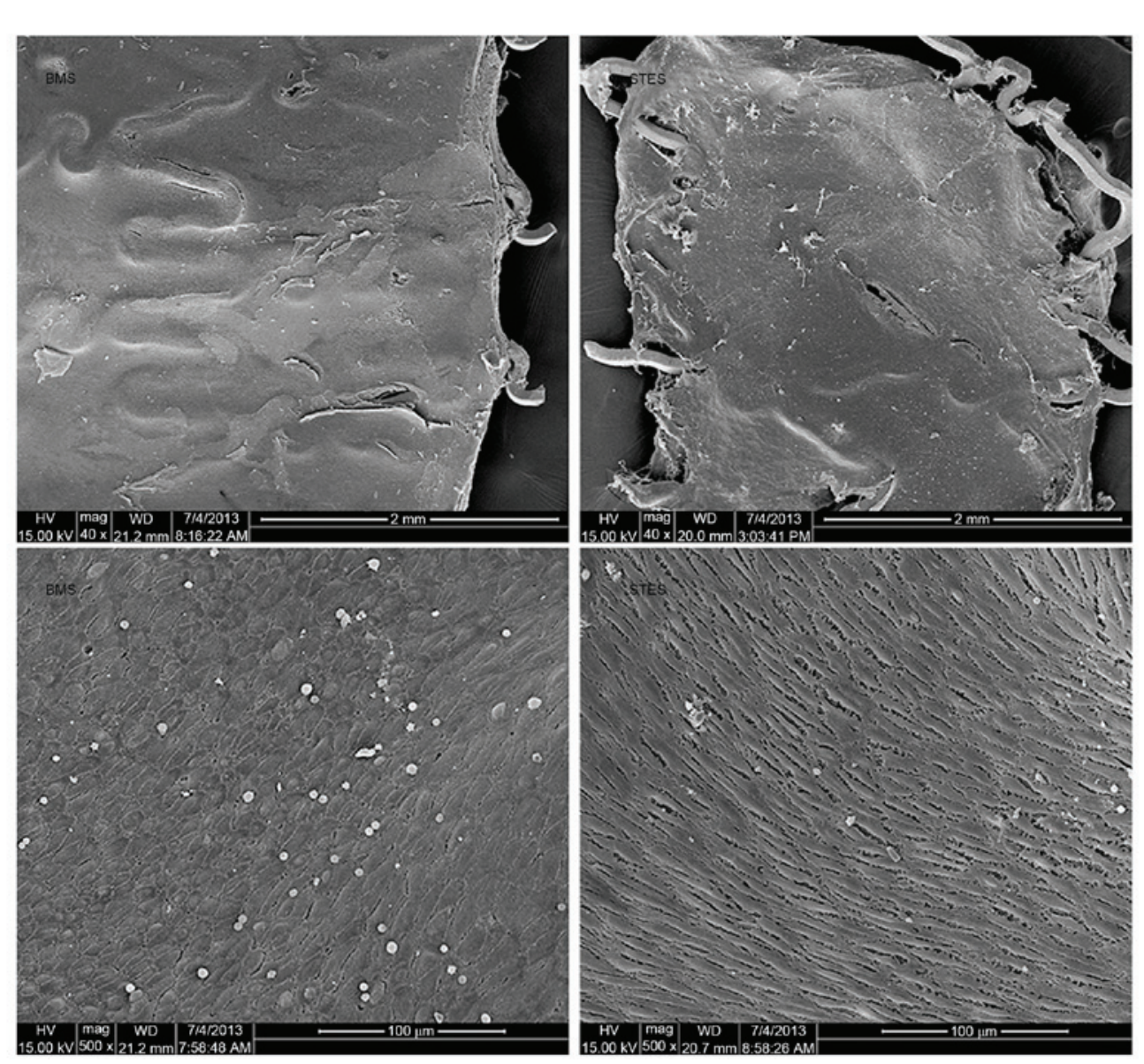
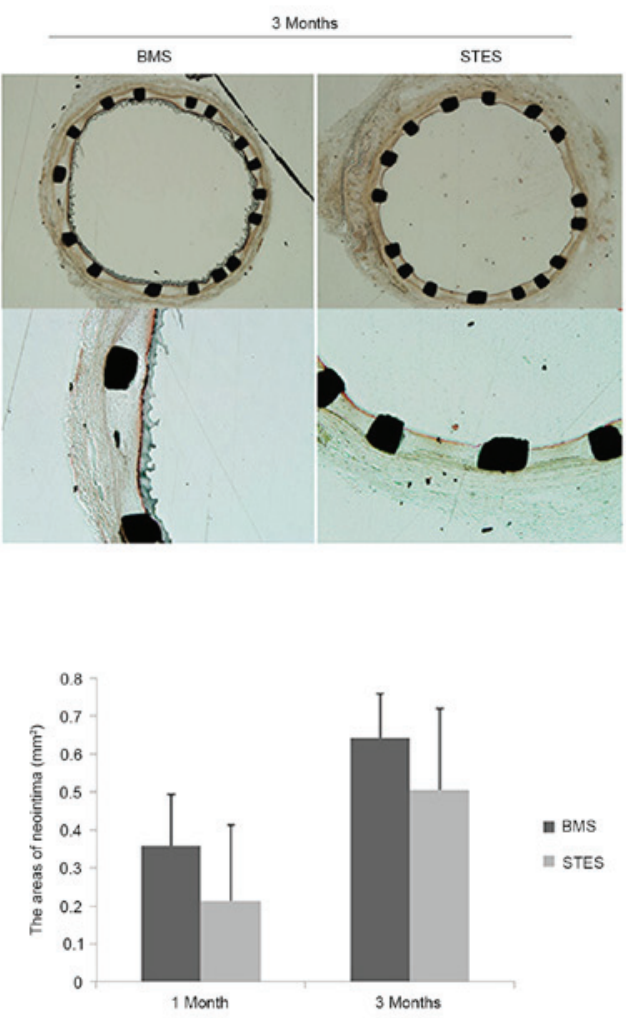

Figure 2. (A) Representative images of hematoxylin and eosin staining of cross-sections one and three months following implantation. (B) Average intimal thickness and the areas of neointima of BMS and STES groups at one and three months post implantation ( $\mathrm{n}=6$ per group). The STES group had reduced intimal thickness and area compared with the BMS group. ${ }^{*} \mathrm{P}<0.05$. (C) Re-endothelialization assessed by en face scanning electron microscopy of the arteries one month following stent implantation. The BMS and the STES were efficient at inducing re-endothelialization. BMS, bare-metal stent; STES, sunitinib-eluting stent; N, neointima; M, media; S, strut. 

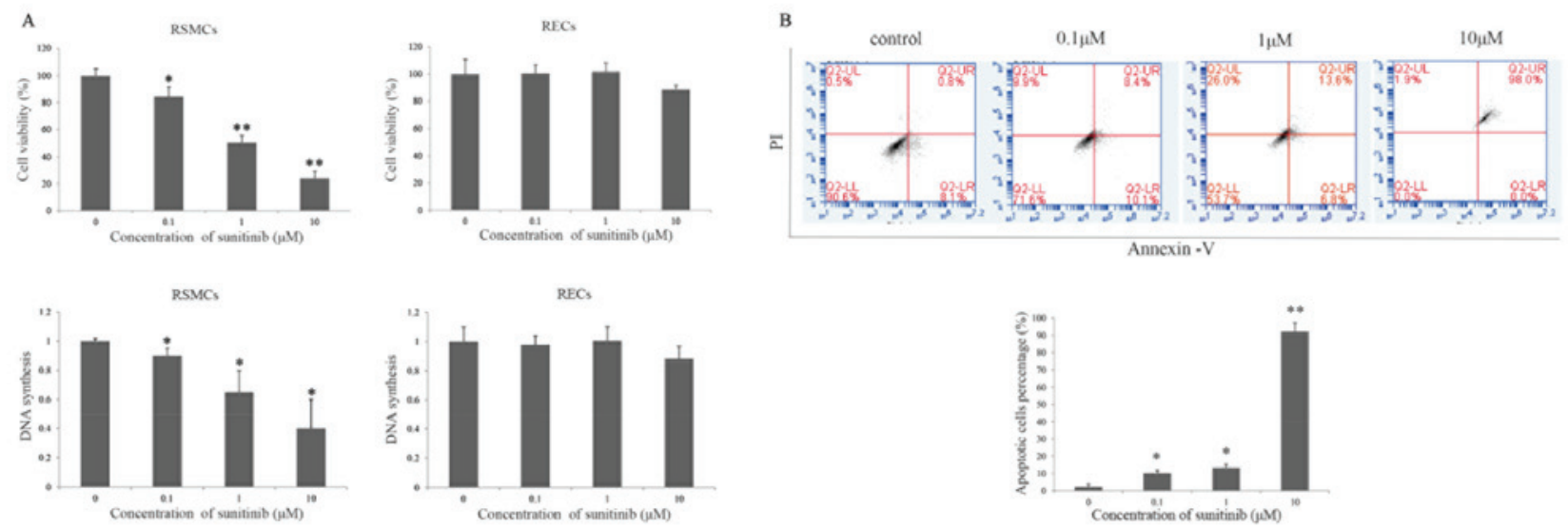

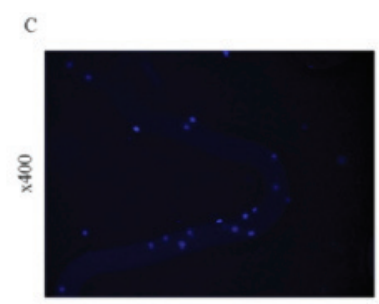

BMS

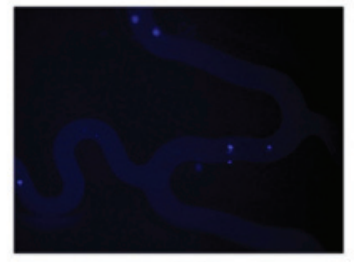

STES

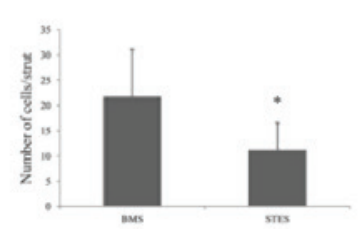

D
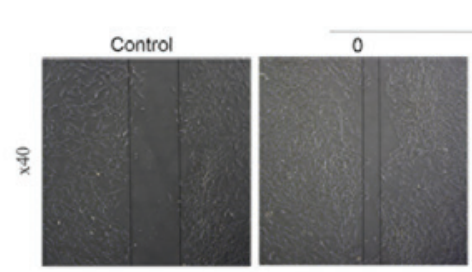

PDGF+Sunitinib

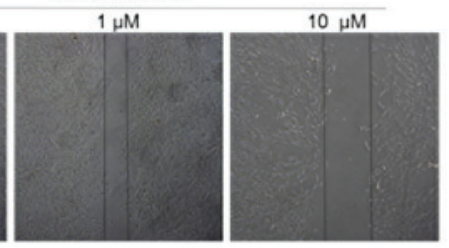

E
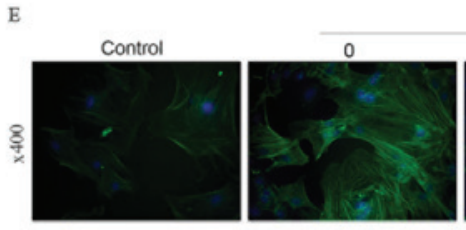

PDGF+Sunitinib

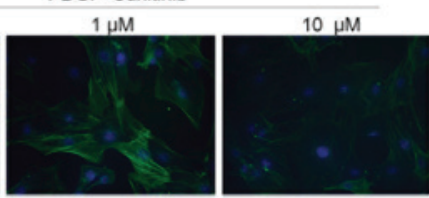

Figure 3. (A) Effect of sunitinib on the proliferation of RSMCs and RECs. Sunitinib inhibited proliferation and DNA synthesis in RSMCs, but not in RECs. "P<0.05 and ${ }^{* *} \mathrm{P}<0.01$ vs. vehicle. (B) Effect of sunitinib on apoptosis and necrosis of PDGF-BB-treated RSMCs. Apoptotic (annexin $\left.\mathrm{V}^{+} / \mathrm{PI}^{-}\right)$or necrotic (annexin $\mathrm{V}^{+} / \mathrm{PI}^{+}$) cells were identified by flow cytometry. ${ }^{*} \mathrm{P}<0.05$ and ${ }^{* *} \mathrm{P}<0.01$ vs. vehicle. (C) Representative images reveal that greater numbers of cells attach to the $\mathrm{BMS}$ compared with the STES. Cell nuclei were stained blue with DAPI. Magnification, $\mathrm{x} 400 .{ }^{*} \mathrm{P}<0.05$ vs. BMS. (D) Representative images reveal that sunitinib attenuated PDGF-induced migration of RSMCs in a scratch wound assay in a dose-dependent manner. Solid lines represent the edges of cell migration. Magnification, $\mathrm{x} 40$. (E) Effect of sunitinib on $\alpha$-SMA cytoskeleton polymerization in RSMCs; $\alpha$-SMA was stained with fluorescein isothiocyanate (green), and nuclei were stained with DAPI (blue). Magnification, x400. RMSCs, rat smooth muscle cells; RECs, rat endothelial cells; PDGF, platelet-derived growth factor; PI, propidium iodide; BMS, bare-metal stent; STES, sunitinib-eluting stent; DAPI, 4',6-diamidino-2-phenylindole; $\alpha$-SMA, $\alpha$-smooth muscle actin.

$\mathrm{P}=0.021 ; 1 \mu \mathrm{M}, \mathrm{P}=0.024 ; 10 \mu \mathrm{M}, \mathrm{P}=0.031 ;$ Fig. $4 \mathrm{~A}$ and $\mathrm{B})$. This suggested that sunitinib specifically inhibited PDGF-induced ERK activation. In the in vivo experiment, the media, adventitia and neointima were harvested. The protein expression levels of p-ERK in the neointima were significantly decreased in STES compared with BMS $(\mathrm{P}=0.027$; Fig. 4C and D).

\section{Discussion}

The importance of the PDGFR signaling pathway in the pathophysiology of atherosclerosis and restenosis following angioplasty has been highlighted by recent studies $(10,13,14)$. The potential to reverse in-stent restenosis through inhibiting this signaling pathway has been investigated $(7,8,21,22)$. The majority of these studies administered PDGFR inhibitors orally. This systemic application may cause unwanted side-effects, including the development of cardiotoxicity. The present study demonstrates that the local application of sunitinib through STES may reduce in-stent restenosis without impairing endothelial regeneration in the carotid model. The estimated dose of sunitinib was $32 \pm 5.4 \mu \mathrm{g} / \mathrm{stent}$, markedly reduced compared with the dose required for oral administration. In addition, sunitinib attenuated the proliferation and migration of SMCs in vitro, potentially via the inhibition of the p-ERK signaling pathway. These results indicate that STES may represent a potential DES for the treatment of in-stent restenosis.

The mechanisms underlying the effect of STES on in-stent restenosis require further investigation prior to its clinical application. The abnormal proliferation of SMCs is a prominent feature of neointimal formation (1). Sunitinib attenuated RSMC proliferation in a dose-dependent manner. As an anti-proliferative effect is often accompanied by apoptosis or necrosis, the apoptotic effects of sunitinib in RSMCs were examined. Sunitinib increased necrosis, indicating that it may inhibit RSMC proliferation via the induction of necrosis. SMC migration from media to intima is another 

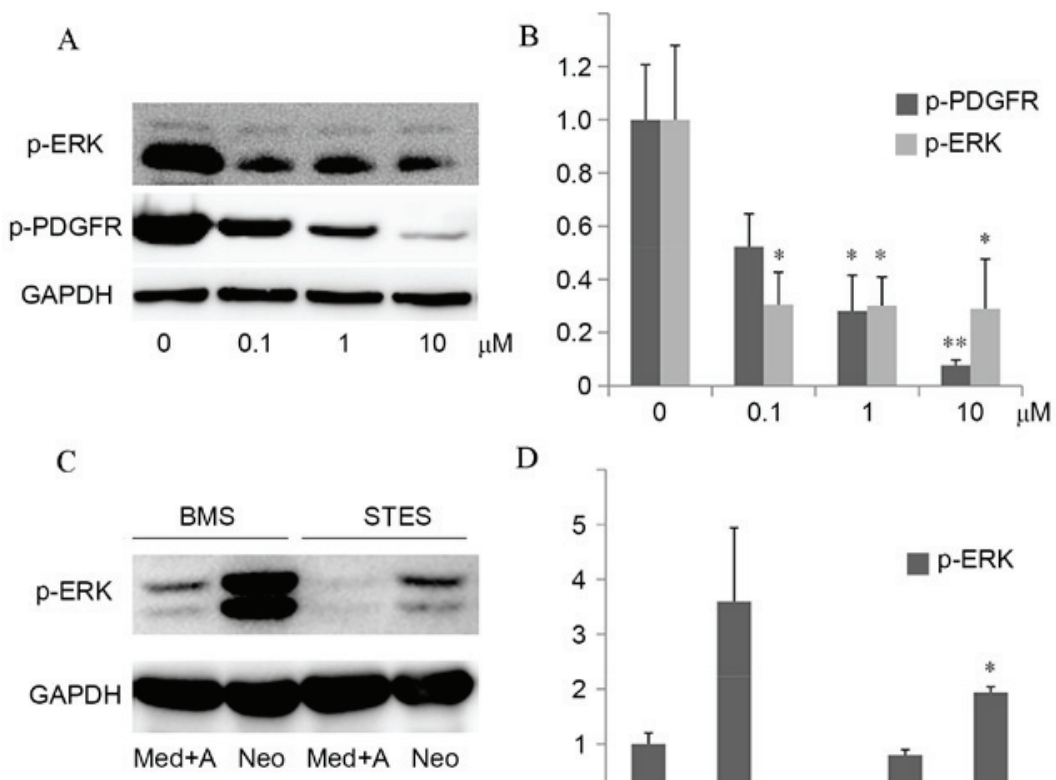

$\mathrm{D}$

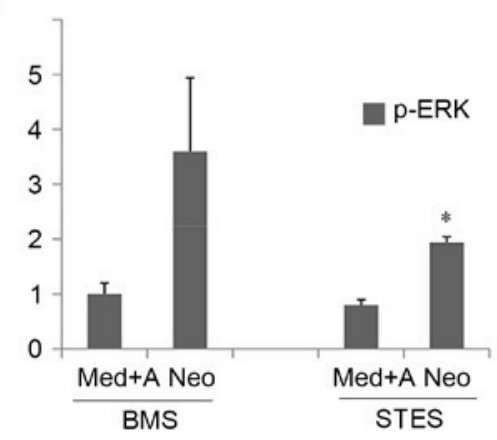

Figure 4. The inhibitory effect of sunitinib on PDGF-induced intracellular signaling in vitro and in vivo. (A) Left panel: RSMCs were stimulated with $20 \mathrm{ng} / \mathrm{ml}$ PDGF-BB and 0-10 $\mu \mathrm{M}$ sunitinib in serum-free medium for $24 \mathrm{~h}$. Western blot analysis of p-ERK, p-PDGFR and GAPDH, which served as a loading control, was performed. (B) Quantification of western blots demonstrated that protein expression levels of p-PDGFR were decreased by sunitinib treatment in a dose-dependent manner, and PDGF-induced downstream p-ERK protein expression levels were suppressed. " $\mathrm{P}<0.05$ and ${ }^{* *} \mathrm{P}<0.01$ vs. vehicle. (C) The media, adventitia and neointima were harvested from rabbits implanted with BMS or STES, and western blot analysis of p-ERK was performed, with GAPDH serving as a loading control. (D) Quantification of western blots demonstrated that protein expression levels of p-ERK in the neointima were significantly decreased in STES compared with BMS. "P<0.05 vs. BMS Neo. PDGF, platelet-derived growth factor; RMSCs, rat smooth muscle cells; p-, phosphorylated; ERK, extracellular signal-regulated kinase; PDGFR, PDGF receptor; BMS, bare-metal stent; STES, sunitinib-eluting stent; Med, media; A, adventitia; Neo, neointima; GAPDH, glyceraldehyde-3-phosphate dehydrogenase.

mechanism underlying restenosis (23); the scratch wound assay and $\alpha$-SMA staining demonstrated the inhibitory effect of sunitinib on RSMC migration. In addition, extracellular matrix production is critical for the development of intimal hyperplasia; future studies in our laboratory will therefore investigate the effect of sunitinib on collagen synthesis.

ERK is an important downstream effector of PDGF-induced SMC migration and proliferation (24). In the present study, sunitinib inhibited PDGF-induced ERK phosphorylation in vitro and in vivo. In addition, other downstream signaling molecules, including protein kinase B and c-Jun $\mathrm{N}$-terminal kinase, may contribute to the inhibitory effect of sunitinib (25-27). These molecules differentially regulate SMC growth and migration via distinct signaling pathways.

Delayed healing and re-endothelialization following implantation are features of DES, which may be the result of adverse effects of the nonspecific antiproliferative agent used (28-30). Theoretically, PDGFR inhibition should not interfere with re-endothelialization, as endothelial cells do not express PDGFR. SEM revealed no differences in re-endothelialization between BMS and STES, suggesting that sunitinib inhibited only RSMC proliferation and neointima formation. Re-endothelialization was almost complete in the present study one month following implantation. In humans, the timescale of re-endothelialization remains to be fully elucidated. Stents implanted in human arteries encounter long, heavily calcified or chronically occluded lesions, and elderly patients have defective endothelial progenitor cells (EPC). Therefore, rapid re-endothelialization is difficult in humans. Certain pro-healing strategies have been developed to promote endothelialization. Stents coated with anti-cluster of differentiation 34 antibodies have demonstrated promise in capturing EPC (31). The combination of the promotion of re-endothelialization and the inhibition of neointima formation may be a potential strategy for the development of novel DES.

Limitations of the present, preliminary, study include the lack of pharmacokinetic data. The tissue distribution and concentration of sunitinib following STES implantation remains unknown. In addition, the division of implanted arteries into three segments for separate analyses may introduce error, as the most rapid re-endothelialization occurs in the proximal region of the stent. Furthermore, the effect of STES was not assessed in a hypercholesterolemic rabbit model. The use of rat instead of human SMCs and ECs may also reduce the clinical relevance of the present study. Further studies are required to evaluate the clinical application of STES.

In conclusion, the results of the present study demonstrate that the inhibition of PDGF signaling by sunitinib attenuated the proliferation and migration of RSMCs but not RECs in vitro, and that STES inhibited in-stent neointimal formation in the rabbit carotid artery in vivo. The results of the present study support the potential use of PDGFR inhibitors in DES. 


\section{References}

1. Costa MA and Simon DI: Molecular basis of restenosis and drug-eluting stents. Circulation 111: 2257-2273, 2005.

2. Lafont A and Libby P: The smooth muscle cell: Sinner or saint in restenosis and the acute coronary syndromes? J Am Coll Cardiol 32: 283-285, 1998.

3. Spaulding C, Henry P, Teiger E, Beatt K, Bramucci E, Carrié D, Slama MS, Merkely B, Erglis A, Margheri M, et al: Sirolimus-eluting versus uncoated stents in acute myocardial infarction. N Eng1 J Med 355: 1093-1104, 2006.

4. Stone GW, Lansky AJ, Pocock SJ, Gersh BJ, Dangas G, Wong SC, Witzenbichler B, Guagliumi G, Peruga JZ, Brodie BR, et al: Paclitaxel-eluting stents versus bare-metal stents in acute myocardial infarction. N Engl J Med 360: 1946-1959, 2009.

5. Serruys PW, Silber S, Garg S, van Geuns RJ, Richardt G, Buszman PE, Kelbaek H, van Boven AJ, Hofma SH,Linke A, et al: Comparison of zotarolimus-eluting and everolimus-eluting coronary stents. N Engl J Med 363: 136-146, 2010.

6. Luscher TF, Steffel J, Eberli FR, Joner M, Nakazawa G, Tanner FC and Virmani R: Drug-eluting stent and coronary thrombosis: Biological mechanisms and clinical implications. Circulation 115: 1051-1058, 2007.

7. Chen J, Han Y, Lin C, Zhen Y, Song X, Teng S, Chen C, Chen Y, Zhang Y and Hui R: PDGF-D contributes to neointimal hyperplasia in rat model of vessel injury. Biochem Biophys Res Commun 329, 976-983, 2005.

8. Nurminskaya M, Beazley KE, Smith EP and Belkin AM: Transglutaminase 2 promotes PDGF-mediated activation of PDGFR/Akt1 and $\beta$-catenin signaling in vascular smooth muscle cells and supports neointima formation. J Vasc Res 51: 418-428, 2014.

9. Zimmermann O, Zwaka TP, Marx N, Torzewski M, Bucher A, Guilliard P, Hannekum A, Hombach V and Torzewski J: Serum starvation and growth factor receptor expression in vascular smooth muscle cells. J Vasc Res 43: 157-165, 2006.

10. Kappert K, Paulsson J, Sparwel J, Leppänen O, Hellberg C, Ostman A and Micke P: Dynamic changes in the expression of DEP-1 and other PDGF receptor-antagonizing PTPs during onset and termination of neointima formation. FASEB J 21: 523-534, 2007.

11. Demetri GD, van Oosterom AT, Garrett CR, Blackstein ME, Shah MH, Verweij J, McArthur G, Judson IR, Heinrich MC, Morgan JA, et al: Efficacy and safety of sunitinib in patients with advanced gastrointestinal stromal tumour after failure of imatinib: A randomised controlled trial. Lancet 368: 1329-1338, 2006.

12. Motzer RJ, Hutson TE, Tomczak P, Michaelson MD, Bukowski RM, Oudard S, Negrier S, Szczylik C, Pili R, Bjarnason GA, et al: Overall survival and updated results for sunitinib compared with interferon alfa in patients with metastatic renal cell carcinoma. J Clin Oncol 27: 3584-3590, 2009.

13. Ishii S, Okamoto Y, Katsumata H, Egawa S, Yamanaka D, Fukushima M and Minami S: Sunitinib, a small-molecule receptor tyrosine kinase inhibitor, suppresses neointimal hyperplasia in balloon-injured rat carotid artery. J Cardiovasc Pharmacol Ther 18: 359-366, 2013.

14. Zohlnhöfer D, Hausleiter J, Kastrati A, Mehilli J, Goos C, Schühlen H, Pache J, Pogatsa-Murray G, Heemann U, Dirschinger J and Schömig A: A randomized, double-blind, placebo-controlled trial on restenosis prevention by the receptor tyrosine kinase inhibitor imatinib. J Am Coll Cardiol 46: 1999-2003, 2005.

15. Chen YX, Ma X, Whitman S and O'Brien ER: Novel antiinflammatory vascular benefits of systemic and stent-based delivery of ethylisopropylamiloride. Circulation 110: 3721-3726, 2004.
16. Lankheet NA, Steeghs N, Rosing H, Schellens JH, Beijnen JH and Huitema AD: Quantification of sunitinib and N-desethyl sunitinib in human EDTA plasma by liquid chromatography coupled with electrospray ionization tandem mass spectrometry: Validation and application in routine therapeutic drug monitoring. Ther Drug Monit 35: 168-176, 2013.

17. Andrés-Manzano MJ, Andrés V and Dorado B: Oil Red O and Hematoxylin and eosin staining for quantification of atherosclerosis burden in mouse aorta and aortic root. Methods Mol Biol 1339: 85-99, 2015.

18. Schwartz RS, Edelman E, Virmani R, Carter A, Granada JF, Kaluza GL, Chronos NA, Robinson KA, Waksman R, Weinberger J, et al: Drug-eluting stents in preclinical studies: Updated consensus recommendations for preclinical evaluation. Circ Cardiovasc Interv 1: 143-153, 2008.

19. Hong MK, Kornowski R, Bramwell O, Ragheb AO and Leon MB: Paclitaxel-coated Gianturco-Roubin II (GR II) stents reduce neointimal hyperplasia in a porcine coronary in-stent restenosis model. Coron Artery Dis 12: 513-515, 2001

20. Kok SH, Gambari R, Chui CH, Lau FY, Cheng GY, Lai PB, Lam WS, Chan AS, Cheng CH, Teo IT, et al: Paradoxical proliferative potential of iron (II) sulphate on cancer cells after the 3-(4,5-dimethylthiazol-2-yl)-5-(3-carboxymethoxyphenyl)-2(4-sulfophenyl)-2H-tetrazolium (MTS) assay. Int J Mol Med 19: 971-975, 2007.

21. Jandt E, Mutschke O, Mahboobi S, Uecker A, Platz R, Berndt A, Böhmer FD, Figulla HR and Werner GS: Stent-based release of a selective PDGF-receptor blocker from the bis-indolylmethanon class inhibits restenosis in the rabbit animal model. Vascul Pharmacol 52: 55-62, 2010.

22. Seo J, Lee HS, Ryoo S, Seo JH, Min BS and Lee JH: Tangeretin, a citrus flavonoid, inhibits PGDF-BB-induced proliferation and migration of aortic smooth muscle cells by blocking AKT activation. Eur J Pharmacol 673: 56-64, 2011.

23. Raines EW: PDGF and cardiovascular disease. Cytokine Growth Factor Rev 15: 237-254, 2004.

24. Hua Y, Dolence J, Ramanan S, Ren J and Nair S: Bisdemethoxycurcumin inhibits PDGF-induced vascular smooth muscle cell motility and proliferation. Mol Nutr Food Res 57: 1611-1618, 2013.

25. Murrell M, Khachigian L and Ward MR: The role of c-jun in PDTC-sensitive flow-dependent restenosis after angioplasty and stenting. Atherosclerosis 194: 364-371, 2007.

26. Jia L, Wang R and Tang DD: Abl regulates smooth muscle cell proliferation by modulating actin dynamics and ERK1/2 activation. Am J Physiol Cell Physiol 302: C1026-C1034, 2012.

27. Cai Y, Knight WE, Guo S, Li JD, Knight PA and Yan C: Vinpocetine suppresses pathological vascular remodeling by inhibiting vascular smooth muscle cell proliferation and migration. J Pharmacol Exp Ther 343: 479-288, 2012.

28. Joner M, Finn AV, Farb A, Mont EK, Kolodgie FD, Ladich E, Kutys R, Skorija K, Gold HK and Virmani R: Pathology of drug eluting stents in humans: Delayed healing and late thrombotic risk. J Am Coll Cardiol 48: 193-202, 2006.

29. Finn AV, Nakazawa G, Joner M, Kolodgie FD, Mont EK, Gold HK and Virmani R: Vascular responses to drug eluting stents: Importance of delayed healing. Arterioscler Thromb Vasc Biol 27: 1500-1510, 2007.

30. Nakazawa G, Finn AV, Joner M, Ladich E, Kutys R, Mont EK, Gold HK, Burke AP, Kolodgie FD and Virmani R: Delayed arterial healing and increased late stent thrombosis at culprit sites after drug-eluting stent placement for acute myocardial infarction patients: An autopsy study. Circulation 118: 1138-1145, 2008.

31. Houtgraaf JH and Duckers HJ: Endothelial progenitor cell (EPC) capture to aid vascular repair following coronary stenting: A new frontier in stent technology? EuroIntervention 4: C67-C71, 2008. 